\title{
Identificação de genótipos do gênero Solanum (secção Lycopersicon) com resistência a Stemphylium solani e S. lycopersici
}

\author{
Bruno Eduardo C de Miranda ${ }^{1}$; Leonardo S Boiteux ${ }^{1.2,3}$; Ailton Reis ${ }^{1,2.3}$ \\ ${ }^{1}$ UnB-Depto Fitopatologia, C. Postal 4457, 70910-900 Brasília-DF; ' ${ }^{2}$ Embrapa Hortaliças, C. Postal 218, 70359-970 Brasília-DF; ${ }^{3}$ Bol- \\ sista Produtividade CNPq (MCT); ailton@enph.embrapa.br
}

\section{RESUMO}

A mancha-de-estenfílio do tomateiro, causada pelos fungos Stemphylium solani e $S$. lycopersici, foi considerada, por muito tempo, como uma doença secundária devido à utilização combinada de fungicidas e variedades resistentes. Recentemente, severas epidemias da mancha-de-estenfilio têm sido relatadas nas várias regiões produtoras sugerindo a necessidade de retomar o emprego de cultivares com resistência a esta enfermidade. O objetivo do presente trabalho foi avaliar a reação de genótipos cultivados e silvestres de tomateiro [Solanum (secção Lycopersicon)] frente a isolados destas duas espécies de Stemphylium. Na primeira etapa do trabalho, 109 genótipos de Solanum (secção Lycopersicon) foram avaliados via inoculação com uma suspensão de $10^{4}$ conídios $/ \mathrm{mL}$ dos isolados 'EH-1740' ( $S$. solani) e 'EH-1749' (S. lycopersici). As plantas foram transplantadas aos 18 dias da semeadura e inoculadas sete dias depois. A avaliação da resposta dos genótipos foi feita 15 dias após a inoculação. Cinqüenta e oito genótipos considerados promissores foram novamente avaliados (com os mesmos isolados) em um segundo experimento. Neste experimento a reação dos genótipos foi avaliada cada dois dias utilizando como critérios o período de incubação e a severidade da doença através de uma escala de notas de 0 a 5 . Com os valores de severidade, nas diferentes leituras, foi calculada a área abaixo da curva de progresso da doença e o índice de doença. Foram identificadas 35 fontes de resistência às duas espécies de Stemphylium em genótipos das espécies $S$. lycopersicum, $S$. habrochaites, $S$. peruvianum e $S$. pimpinellifolium. Os genótipos de $S$. lycopersicum e $S$. pimpinellifolium resistentes possuem, provavelmente, o gene de resistência $S m$. No entanto, os genótipos de $S$. peruvianum e $S$. habrochaites podem representar fontes de novos genes/alelos que conferem resistência às duas espécies fúngicas. Esta potencial diversidade de fatores de resistência para Stemphylium pode ser útil em futuras ações de pesquisa dentro de programas de melhoramento genético do tomateiro bem como para o manejo integrado da doença.

Palavras-chave: Solanum lycopersicum, gene Sm, mancha-deestenfílio, resistência genética, tomate.

\begin{abstract}
Identification of Solanum (section Lycopersicon) accessions with resistance to Stemphylium solani and $S$. lycopersici

The gray leaf spot disease, caused by the fungi Stemphylium solani and $S$. lycopersici, has been considered as a minor tomato disease in Brazil due to the use of varieties with genetic resistance in combination with fungicide sprays. However, recent reports of severe epidemics of the gray leaf spot in the various tomatoproducing areas of the country suggest that the employment of resistant cultivars should be re-implemented as a control strategy. In the present study, 109 cultivated and wild Solanum (section Lycopersicon) accessions were evaluated to isolates of both $S$. solani and $S$. lycopersici. In the first assay, spore suspension (adjusted to $10^{4}$ conidia/mL) of the isolates 'EH-1740' (S. solani) and 'EH-1749' ( $S$. lycopersici) were employed to inoculate seedlings transplanted 15 days after sowing and kept in a greenhouse. Plants were inoculated 18 days after transplanting and evaluated 15 days after inoculation. Fifty-eight promising accessions identified in the first assay were evaluated again with the same isolates in a second experiment. The reaction of the accessions to the pathogens was evaluated every two days using as assessment criteria the incubation period, the severity of gray leaf spot, and the disease index. Disease severity values over time were used to calculate the area under the disease progress curve. Promising sources of resistance to both pathogens were identified in accessions of $S$. lycopersicum, S. habrochaites, $S$. peruvianum and $S$. pimpinellifolium. The resistant sources identified in S. pimpinellifolium and S. lycopersicum accessions probably have the gene Sm. However, S. habrochaites and S. peruvianum might be potential new sources of gene/alleles that confer resistance to both fungi. This diversity of Stemphylium resistance genes might be useful for tomato breeding programs in the future as well as in integrated management systems of the disease.
\end{abstract}

Keywords: Solanum lycopersicum, Sm gene, gray leaf spot, genetic resistance, tomato .

(Recebido para publicação em 15 de abril de 2009; aceito em 20 de maio de 2010)

(Received on April 15, 2009; accepted on May 20, 2010)

E m escala global, o tomateiro (Solanum lycopersicum L.) é uma das principais hortaliças em termos de área de plantio, consumo e importância sócio-econômica, sendo que o Brasil figura como um dos principais produtores (Giordano et al., 2003). A cultura do tomateiro é afetada por doenças de diferentes etiologias, sendo que os fungos e pseudofungos são responsáveis por mais de $90 \%$ delas (Lopes et al., 2005). A mancha foliar cinza ou mancha-de-estenfílio tem se destacado, nos últimos anos, como uma das principais doenças fúngicas desta hortaliça (Reis \& Boiteux, 2006a; 2006b). Diferentes espécies do gênero Stemphylium (sensu Wiltshire, 1938) têm sido reportadas causando manchas foliares no tomateiro em diferentes regiões do mundo. As espécies fúngicas descritas incluem: S. solani (Weber, 1930); S. lycopersici (Ellis \& Gibson 1975b); S. floridanum (Hannon \& Weber, 1955) e S. botryosum (Rotem et al., 1966). No entanto, as espécies predominantes no Brasil e no mundo são $S$. solani (Weber, 1930; Ellis \& Gibson 1975a; Blancard \& Laterrot, 1986) e S. lycopersici (Ellis \& Gibson 1975b; Blancard \& Laterrot, 1986). 
Os sintomas da mancha-de-estenfílio podem ser observados nos cotilédones de plântulas ainda na fase de sementeira, assim como durante todos os demais estádios de desenvolvimento da cultura. No entanto, os sintomas se intensificam no início da colheita. Os propágulos (conídios e fragmentos de micélio) dos patógenos podem ser disseminados via mudas doentes ou por insetos. No entanto, o vento é o principal meio de disseminação planta-planta dentro da lavoura (Azevedo, 2003; Reis \& Boiteux, 2006a). As espécies de Stemphylium podem sobreviver em restos de cultura no solo, em plantas de crescimento espontâneo ("ressocas" ou "tigüeras") bem como em mudas velhas abandonadas em viveiros. Além disso, diversas espécies cultivadas e silvestres do gênero Solanum têm sido identificadas como hospedeiras alternativas dos fungos causadores da mancha-deestenfílio, podendo, desta forma, servir como fontes perenes e semi-perenes de inóculo para o tomateiro (Boiteux et al., 1993; Reis \& Boiteux, 2006a).

Nas últimas décadas, a mancha-deestenfílio tem sido considerada como uma doença secundária devido ao uso combinado de variedades resistentes e às aplicações periódicas de fungicidas para controle do complexo de doenças foliares que afetam normalmente o tomateiro nas condições brasileiras (Lopes et al., 2005). No entanto, epidemias severas do patógeno foram verificadas recentemente nas principais regiões produtoras de tomate do Brasil (Reis \& Boiteux, 2006a). O ressurgimento de uma doença secundária nas regiões produtoras sugere duas situações: (1) potenciais erros de diagnose de $S$. solani e $S$. lycopersici como agentes causais da doença, resultando na adoção de estratégias inadequadas de controle químico e (2) falta de interesse e/ou ausência de prioridade das empresas de sementes em desenvolver cultivares contendo o gene de resistência $S m$, que confere resistência à espécies de Stemphylium (Behare et al., 1991). De fato, respostas de extrema suscetibilidade a S. solani e $S$. lycopersici têm sido observadas na maioria dos híbridos comerciais atualmente cultivados no Brasil. Um recente levantamento foi conduzido com
50 cultivares de tomateiro (disponíveis em catálogos de diferentes empresas de sementes que atuam no Brasil) sobre a utilização de resistência genética contra mancha-de-estenfílio. O resultado deste levantamento indicou que apenas 16 cultivares (32\%) apresentavam resistência genética à doença (Reis \& Boiteux, 2006a). Entre as cultivares suscetíveis, encontram-se muitas cultivares líderes de mercado (Reis \& Boiteux, 2006a).

Diferentes espécies do gênero Solanum (secção Lycopersicon) têm sido utilizadas em programas de melhoramento genético do tomateiro visando à incorporação de genes que conferem resistência a pragas e doenças. Genes dominantes têm sido relatados capazes de controlar pelo menos doze doenças que potencialmente limitam a produção da cultura, incluindo o gene $\mathrm{Sm}$ para resistência a Stemphylium spp. (Giordano et al., 2003). As características monogênicas e dominantes desses genes facilitam o desenvolvimento de híbridos F1 com resistência a doenças. Genótipos selvagens de tomateiro podem ser resistentes à mancha-de-estenfílio, provavelmente também possuindo o gene $S m$ ou alguma variante alélica deste gene (Giordano et al., 2003).

O presente trabalho teve como objetivo expandir a avaliação e buscar novas fontes de resistência às duas principais espécies fúngicas causadoras da mancha-de-estenfílio ( $S$. solani e $S$. lycopersici) em um germoplasma de base genética ampla, composto por acessos de diferentes espécies de Solanum (secção Lycopersicon).

\section{MATERIAL E MÉTODOS}

\section{Produção de inóculo de Stem-} phylium solani e $S$. lycopersici - A produção de inóculo seguiu o protocolo proposto por Rodrigues (2005), com algumas modificações. Um isolado de S. solani ('EH-1740') e outro de S. lycopersici ('EH-1749') foram cultivados em meio V8 + rifampicina (antibiótico) até o crescimento abundante de micélio. Retirou-se um disco de $10 \mathrm{~mm}$ de cada isolado e colocou-se em frascos do tipo Erlenmeyer contendo $100 \mathrm{~mL}$ do meio líquido batata-dextrose (BD). Os frascos foram colocados em agitador por sete dias a $25^{\circ} \mathrm{C}$ (no escuro). Em seguida, o meio contendo abundante quantidade de micélio (de coloração escura), foi homogeneizado através de um triturador Ace Homogenizer ${ }^{\circledR}$ (Nissei) por dois minutos à velocidade de 20.000 RPM, até se obter uma suspensão homogênea. Verteu-se esta suspensão de micélio triturado em placas de Petri contendo meio V8 + rifampicina. Em seguida, as placas foram deixadas abertas e colocadas em BOD sob 12 horas de escuro e 12 horas de luz negra à temperatura de $25^{\circ} \mathrm{C}$. Após três a quatro dias, removeram-se os esporos (conídios) em água estéril, filtrou-se a suspensão em gaze dupla e ajustou-se a concentração do inóculo para $10^{4}$ conídios $/ \mathrm{mL}$.

Inoculação e avaliação de genótipos de tomateiro aos isolados de Stemphylium - A seleção de genótipos resistentes seguiu o protocolo proposto por Santos (1999), com modificações. O experimento foi conduzido em casa de vegetação da Embrapa Hortaliças, localizada em Brasília (DF). Na primeira etapa do trabalho, 109 genótipos de tomateiro do banco de germoplasma da Embrapa Hortaliças foram avaliados quanto à resistência aos dois isolados de Stemphylium (Tabela 1). Os genótipos utilizados como padrões foram as cultivares de tomateiro 'Ponderosa' (suscetível) e 'Floradade' (resistente devido à presença do gene $\mathrm{Sm}$ ). As sementes foram semeadas em bandejas de poliestireno, contendo substrato para produção de hortaliças $\left(\right.$ Plantmax $\left.^{\circledR}\right)$. As mudas foram transplantadas aos 18 dias após a semeadura para vasos de 1,5 L contendo solo esterilizado. A inoculação foi feita após uma semana do transplantio, no estágio de dois a três pares de folhas verdadeiras. As plantas foram pulverizadas com a suspensão de esporos dos isolados preparados anteriormente, até o ponto de escorrimento da mistura da superfície foliar. Em seguida, as plantas foram mantidas em câmara úmida por 24 horas. Após a retirada da câmara úmida, as plantas foram mantidas em casa de vegetação. $\mathrm{O}$ delineamento foi em blocos ao acaso com dois vasos. A parcela experimental foi constituída de um vaso com quatro plantas. Aos 15 dias após a inoculação, 
os genótipos foram avaliados com base na presença ou ausência de manchas foliares típicas da doença. Foram considerados suscetíveis os genótipos que apresentavam manchas circulares, grandes (de coloração marrom-escura). Foram considerados resistentes os genótipos que apresentavam folhas completamente isentas de sintomas (resistência do tipo imunidade), ou algumas vezes pequenas manchas de $1 \mathrm{~mm}$ com pontuações necróticas no centro da mancha, similar a reações do tipo hipersensibilidade.

Segundo experimento de avaliação de materiais potencialmente resistentes a S. solani e S. lycopersici - Um segundo experimento foi conduzido para confirmar a resistência dos genótipos selecionados no primeiro ensaio e caracterizar se a resistência aos isolados de diferentes espécies de Stemphylium era do tipo imunidade ou qualitativa. Para isso, foram quantificados os seguintes parâmetros epidemiológicos: período de incubação (PI), área abaixo da curva do progresso da doença (AACPD) e a severidade final. Foram selecionados 58 genótipos que apresentaram maior resposta de resistência no primeiro ensaio. A produção de mudas dos genótipos, produção de inóculo e o sistema de inoculação seguiram a mesma metodologia descrita anteriormente. $\mathrm{O}$ delineamento foi em blocos ao acaso com três repetições. A parcela experimental constituiu-se de um vaso com quatro plantas. A severidade da doença foi avaliada a partir do surgimento dos sintomas (PI) em 'Ponderosa', a cada dois dias, durante quatorze dias, num total de sete avaliações. A reação dos genótipos, em cada avaliação, foi mensurada por meio da escala diagramática proposta por Boff et al. (1993); variando de 0 a 5 , correspondendo a $0 \%, 2 \%, 4 \%$, $8 \%, 16 \%$ e $32 \%$ da área foliar lesionada, respectivamente. A partir destes dados foi calculada a área abaixo da curva de progresso da doença (AACPD) para cada um dos genótipos avaliados. A AACPD foi calculada utilizando a seguinte expressão (Fry, 1978): AACPD $=\Sigma\left(\mathrm{y}_{\mathrm{i}}+\mathrm{y}_{\mathrm{i}+1}\right) / 2 \mathrm{xd}_{\mathrm{ti}}$, onde $\mathrm{y}_{\mathrm{i}}$ e $\mathrm{y}_{\mathrm{i}+1}$ são os valores da severidade observados em duas avaliações consecutivas e $\mathrm{d}_{\mathrm{ti}} \mathrm{O}$ intervalo entre as avaliações (em dias). A severidade final (Kurozawa \& Mussi,
1995) foi avaliada através da adaptação da escala de Boff et al. (1993) onde: 0 $=$ folhas sem sintomas; $1=$ até $4 \%$ da área foliar lesionada; $2=$ de 4,1 a $8 \%$ da área foliar lesionada; $3=$ de 8,1 a $16 \%$ da área foliar lesionada; $4=$ de 16,1 a $32 \%$ da área foliar lesionada e 5 = área foliar lesionada acima de 32\%. Com base nestes valores, foi calculado o índice da doença (ID), através da fórmula de McKinney (1923), onde ID (\%) $=100 . \mathrm{S}[(f . v) /(n . x)]$; sendo $f=$ número de plantas com a mesma nota; $v=$ nota observada; $n=$ número total de plantas avaliadas e $x=$ nota máxima da escala (Dalbosco et al., 2002). Os genótipos que não demonstravam sintomas da mancha-de-estenfílio tiveram o PI ajustados para 15 dias, correspondendo ao período de avaliação total (14) mais um dia, conforme proposto por Iamsupasit et al. (1993). Os dados de PI, AACPD e ID foram submetidos à análise de variância (ANOVA) e ao teste de agrupamentos de médias Scott-Knott através do programa de análises estatísticas (Sisvar versão 4.2. DEX/UFLA, 2003). O teste de correlação ( $1 \%$ de probabilidade) para os parâmetros epidemiológicos testados foi feito através do programa ASSISTAT (Silva \& Azevedo, 2002).

\section{RESULTADOS E DISCUSSÃO}

No primeiro ensaio, 49,5\% dos genótipos demonstraram resistência aos isolados das duas espécies fúngicas (Figura 1). As cultivares 'Ponderosa' ('CNPH-0878') e 'Floradade' ('CNPH0010’) apresentaram extrema suscetibilidade e resistência, respectivamente, confirmando a virulência dos isolados. A maioria dos genótipos avaliados para os dois patógenos apresentou reações similares, sendo ou resistentes ou suscetíveis às duas espécies fúngicas. Foram encontrados apenas dois genótipos que apresentaram resistência a apenas uma espécie do patógeno. Esta reação, no entanto, não foi confirmada no segundo ensaio para estes genótipos. Foi verificada, a presença de plantas suscetíveis e resistentes em alguns genótipos (2,7\% do total), sendo esta reação considerada como intermediária ou segregante. Foram identificados genótipos resistentes a S. solani e S. lycopersici nas espécies $S$. lycopersicum, S. habrochaites, S. chilense, S. pimpinellifolium e $S$. peruvianum. Os genótipos de $S$. lycopersicum e $S$. pimpinellifolium avaliados, que foram resistentes, provavelmente possuem o gene de resistência $S m$ (Behare et al., 1991). No entanto, os genótipos de $S$. peruvianum, $S$. chilense e $S$. habrochaites podem representar novas fontes de genes/alelos que conferem resistência às duas espécies fúngicas.

Entre os genótipos avaliados no segundo experimento, 'CNPH-0878' (Ponderosa) e 'CNPH-0782' apresentaram menor PI para todos os isolados inoculados. Os valores de PI, AACPD e do ID para os genótipos inoculados com os isolados 'EH-1740' e 'EH1749’ encontram-se na Tabela 1. Frente ao isolado 'EH-1740', 40 genótipos apresentaram PI máximo, que foi de 15 dias. Frente ao isolado 'EH-1749', 36 isolados apresentaram PI máximo. A diferenciação dos genótipos de acordo com o PI foi significativa pelo teste de Scott-Knott $(p=0,05)$.

A análise de variância foi significativa para a ACPD e o teste de médias de Scott-Knott $(p=0,05)$, permitiram observar uma clara diferenciação dos genótipos (Tabela 1). O padrão de suscetibilidade ('Ponderosa') esteve entre os genótipos que apresentaram maior AACPD, enquanto que o padrão de resistência ('Floradade') apresentou AACPD valor zero. Os maiores valores de AACPD frente ao isolado 'EH-1740' foram observados nos genótipos 'CNPH-0374' e 'CNPH-0781' e os menores valores foram observados nos genótipos 'CNPH-0928' e 'CNPH0981'. Frente ao isolado 'EH-1749', os maiores valores foram observados em 'CNPH-0782' e 'CNPH-0935' e os menores valores em 'CNPH-0969' e 'CNPH-0784'.

O teste de Scott-Knott $(p=0,05)$ também permitiu diferenciação dos genótipos para o ID. Os maiores valores de ID frente ao isolado ' $\mathrm{EH}-1740$ ' foram também observados para os genótipos 'CNPH-0374' e 'CNPH-0781'. Os menores valores foram observados nos genótipos 'CNPH-1467' e 'CNPH1561'. Para o isolado 'EH-1749', os maiores valores foram observados em 'CNPH-0782' e 'CNPH-0935' e os 


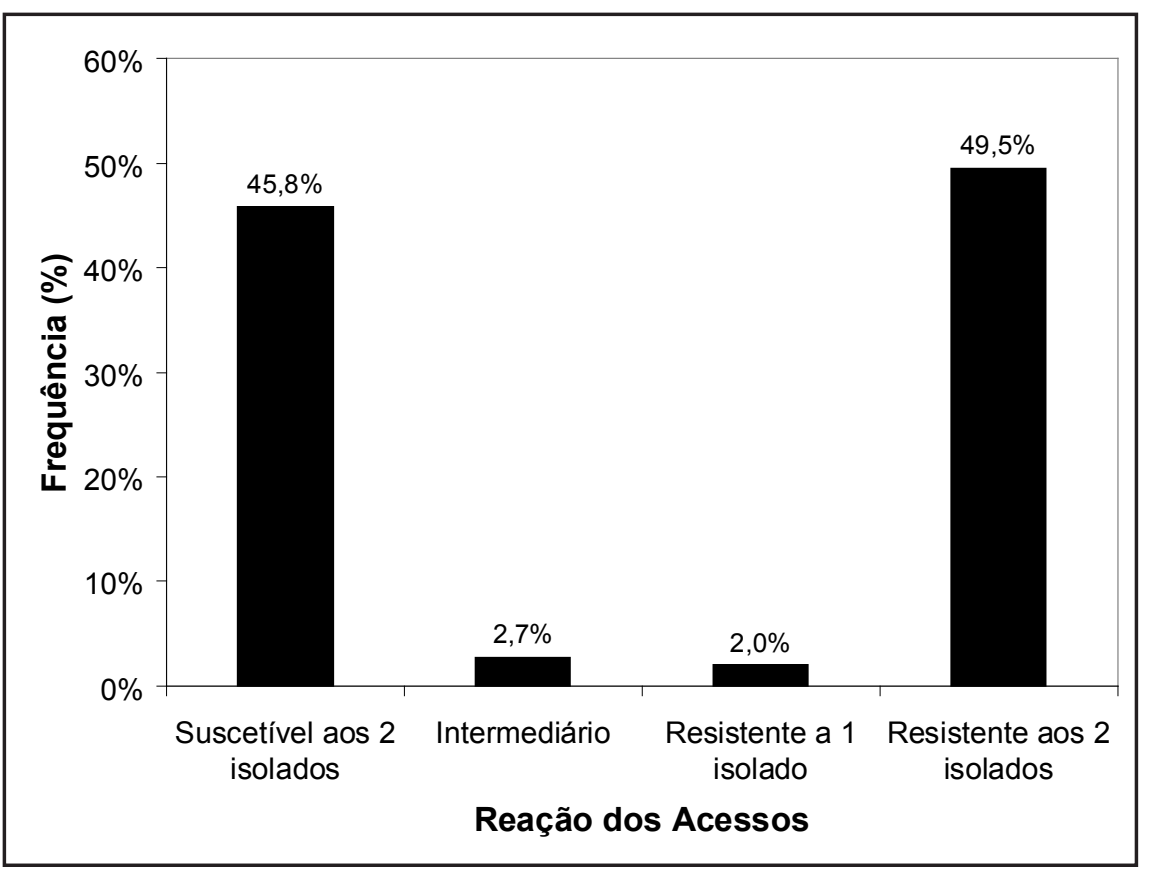

Figura 1. Freqüência de genótipos de espécies de tomateiro [Solanum (secção Lycopersicon)] com resistência e/ou susceptibilidade aos isolados de Stemphylium solani e/ou $S$. lycopersici (frequency of accessions from Solanum (section Lycopersicon) with resistance and/or susceptibility to isolates of either Stemphylium solani or S. lycopersici). Brasília, Embrapa Hortaliças, 2009.

menores nos genótipos ‘CNPH-0417' e 'CNPH-0427'. Foram constatadas correlações significativas $(p=0,01)$ entre todos os componentes epidemiológicos avaliados. Para o PI comparado ao ID e à AACPD a correlação ficou em torno de $60 \%$ a $80 \%$ e foi negativa. Entre o ID e a AACPD ela foi de 96 a $98 \%$ e foi positiva.

Seis genótipos apresentaram uma aparente reação diferencial às duas espécies de Stemphylium no segundo experimento deste trabalho (Tabela 1). Os genótipos 'CNPH -1112', 'CNPH1195', 'CNPH-1561' e 'CNPH-1563' apresentaram menor PI e maiores AACPD e ID para o isolado 'EH-1749' quando comparados com a resposta ao isolado ' $\mathrm{EH}-1740$ '. Entretanto, como a AACPD e o ID foram baixos, atribui-se isto a uma reação de hipersensibilidade, que confere pequenas manchas necróticas nas plantas inoculadas. Por outro lado, os genótipos 'CNPH-0439' e 'CNPH-0935' apresentaram reação diferencial com altos níveis de AACPD e ID para apenas um dos isolados utilizados. Isto pode indicar que estes dois genótipos possuem diferentes genes/alelos de resistência com especificidade para uma das espécies fúngicas. Para testar
1012', 'CNPH-1013', 'CNPH-1014' e 'CNPH-1020') deve-se ao fato de que eles são derivados de cruzamentos com 'IPA-5', que é uma cultivar que possui resistência estável a $S$. solani e $S$. lycopersici devido à presença do gene $\mathrm{Sm}$ (Laterrot \& Blancard, 1983), sugerindo a transferência desta resistência genética para estes genótipos.

É interessante notar que, apesar de $S$. pimpinellifolium ser a fonte original do gene Sm (Hendrix et al., 1946; Hendrix \& Frazier, 1949), vários genótipos desta espécie foram classificados, no presente ensaio, como suscetíveis aos dois patógenos, confirmando observações feitas anteriormente por Reis \& Boiteux (2006b). Um grande número de genótipos resistentes também foi identificado dentro das espécies $S$. habrochaites e $S$. peruvianum. Muitos destes genótipos, principalmente das espécies $S$. habrochaites e $S$. peruvianum, ainda não haviam sido relatados como resistentes a $S$. solani e S. lycopersici. Estes genótipos podem representar novas fontes de resistência, podendo ser utilizadas como doadoras de novos genes ou distintos alelos do gene $\mathrm{Sm}$.

No geral, genótipos que apresentaram um período de incubação (PI) maior deveriam ser classificados como resistentes e aqueles com um período menor deveriam ser classificados como suscetíveis. Entretanto, alguns genótipos que demonstraram um PI menor apresentaram índice de doença baixo. Em experimentos conduzidos por Pelletier \& Fry (1989), observou-se que cultivares de batata com resistência ao fungo Alternaria solani também apresentaram PI significativamente menores que os apresentados em cultivares suscetíveis. Apesar disto, em alguns patossistemas, $\mathrm{o}$ PI é considerado como um componente importante para a avaliação de resistência de plantas em condições controladas (Dalla Pria et al., 2003; Pedrosa et al., 2004). Outra possível razão é que estes genótipos podem ter apresentado uma reação de hipersensibilidade e não de suscetibilidade. De fato, Bentes \& Matsuoka (2005), através de técnicas de microscopia eletrônica, verificaram que folhas da cultivar de tomateiro 'Montelle' (resistente ao patógeno devido ao gene $\mathrm{Sm}$ ) apresentavam o colapso de 
Tabela 1. Reação de espécies de Solanum (secção Lycopersicon) a um isolado Stemphylium solani ('EH -1740') e um de S. lycopersici ('EH -1749') (reaction of Solanum (section Lycopersicon) accessions to Stemphylium solani isolate 'EH-1740' and S. lycopersici isolate 'EH -1749'). Brasília, Embrapa Hortaliças, 2009.

\begin{tabular}{|c|c|c|c|c|c|c|c|}
\hline Genótipo & Espécie de Solanum & PI & $\begin{array}{l}\text { EH-1740 } \\
\text { (AACPD) }\end{array}$ & ID & PI & $\begin{array}{l}\text { EH-1749 } \\
\text { (AACPD) }\end{array}$ & ID \\
\hline CNPH 0878 & $\mathrm{~S}$, lycopersicum & $3,00 \mathrm{a}$ & 116,001 & $80,00 \mathrm{f}$ & $3,00 \mathrm{a}$ & $86,67 \mathrm{~h}$ & $80,0 \mathrm{f}$ \\
\hline CNPH 0782 & S. peruvianum & $3,00 \mathrm{a}$ & $25,33 \mathrm{f}$ & $26,67 \mathrm{~d}$ & $3,00 \mathrm{a}$ & $90,67 \mathrm{~h}$ & $100,0 \mathrm{~g}$ \\
\hline CNPH 1011 & S. lycopersicum & $3,67 \mathrm{a}$ & $26,67 \mathrm{f}$ & $20,00 \mathrm{c}$ & $3,00 \mathrm{a}$ & $32,00 \mathrm{~d}$ & $20,0 \mathrm{c}$ \\
\hline CNPH 1277 & S. peruvianum & $3,67 \mathrm{a}$ & $36,00 \mathrm{~h}$ & $20,00 \mathrm{c}$ & $3,00 \mathrm{a}$ & $68,00 \mathrm{~g}$ & $60,0 \mathrm{e}$ \\
\hline CNPH 1123 & S. pimpinellifolium & $4,00 \mathrm{a}$ & $22,00 \mathrm{e}$ & $14,00 \mathrm{~b}$ & $6,67 \mathrm{~b}$ & $49,33 \mathrm{e}$ & $40,0 \mathrm{~d}$ \\
\hline CNPH 1238 & S. chilense & $5,00 \mathrm{a}$ & $18,00 \mathrm{~d}$ & $20,00 \mathrm{c}$ & $6,00 \mathrm{~b}$ & $60,00 \mathrm{f}$ & $60,0 \mathrm{e}$ \\
\hline CNPH 1498 & S. peruvianum & $6,00 \mathrm{~b}$ & $18,00 \mathrm{~d}$ & $20,00 \mathrm{c}$ & $3,00 \mathrm{a}$ & $18,00 \mathrm{~b}$ & $20,0 \mathrm{c}$ \\
\hline CNPH 0785 & S. peruvianum & $6,00 \mathrm{~b}$ & $10,00 \mathrm{~b}$ & $20,00 \mathrm{c}$ & $8,00 \mathrm{c}$ & $28,00 \mathrm{c}$ & $20,0 \mathrm{c}$ \\
\hline CNPH 0800 & S. peruvianum & $6,00 \mathrm{~b}$ & $32,00 \mathrm{~g}$ & $20,00 \mathrm{c}$ & $14,00 \mathrm{e}$ & $2,00 \mathrm{a}$ & $20,0 \mathrm{c}$ \\
\hline CNPH 1452 & S. peruvianum & $6,00 \mathrm{~b}$ & $28,00 \mathrm{f}$ & $20,00 \mathrm{c}$ & $6,00 \mathrm{~b}$ & $56,00 \mathrm{e}$ & $60,0 \mathrm{e}$ \\
\hline CNPH 1445 & S. peruvianum & $6,00 \mathrm{~b}$ & $52,00 \mathrm{i}$ & $60,00 \mathrm{e}$ & $3,00 \mathrm{a}$ & $54,67 \mathrm{e}$ & $60,0 \mathrm{e}$ \\
\hline CNPH 1046 & S. lycopersicum & $8,00 \mathrm{c}$ & $14,00 \mathrm{c}$ & $20,00 \mathrm{c}$ & $6,00 \mathrm{~b}$ & $14,00 \mathrm{~b}$ & $20,0 \mathrm{c}$ \\
\hline CNPH 0865 & S. lycopersicum & $8,00 \mathrm{c}$ & $13,33 \mathrm{c}$ & $20,00 \mathrm{c}$ & $8,00 \mathrm{c}$ & $18,00 \mathrm{~b}$ & $20,0 \mathrm{c}$ \\
\hline CNPH 0866 & S. lycopersicum & $8,00 \mathrm{c}$ & $16,00 \mathrm{c}$ & $26,67 \mathrm{~d}$ & $3,00 \mathrm{a}$ & $26,67 \mathrm{c}$ & $20,0 \mathrm{c}$ \\
\hline CNPH 0374 & S. peruvianum & $8,00 \mathrm{c}$ & $108,00 \mathrm{k}$ & $80,00 \mathrm{f}$ & $3,00 \mathrm{a}$ & $33,33 \mathrm{~d}$ & $20,0 \mathrm{c}$ \\
\hline CNPH 0781 & S. peruvianum & $8,00 \mathrm{c}$ & $108,00 \mathrm{k}$ & $80,00 \mathrm{f}$ & $6,00 \mathrm{~b}$ & $52,00 \mathrm{e}$ & $40,0 \mathrm{~d}$ \\
\hline CNPH 0439 & S. lycopersicum & $8,00 \mathrm{c}$ & $56,00 \mathrm{j}$ & $60,00 \mathrm{e}$ & $15,00 \mathrm{f}$ & $0,00 \mathrm{a}$ & $0,0 \mathrm{a}$ \\
\hline CNPH 0928 & S. habrochaites & $14,00 \mathrm{~d}$ & $2,00 \mathrm{~b}$ & $20,00 \mathrm{c}$ & $15,00 \mathrm{f}$ & $0,00 \mathrm{a}$ & $0,0 \mathrm{a}$ \\
\hline CNPH 0981 & S. peruvianum & $15,00 \mathrm{e}$ & $0,00 \mathrm{a}$ & $0,00 \mathrm{a}$ & $15,00 \mathrm{f}$ & $0,00 \mathrm{a}$ & $0,0 \mathrm{a}$ \\
\hline CNPH 0663 & S. lycopersicum & $15,00 \mathrm{e}$ & $0,00 \mathrm{a}$ & $0,00 \mathrm{a}$ & $15,00 \mathrm{f}$ & $0,00 \mathrm{a}$ & $0,0 \mathrm{a}$ \\
\hline CNPH 1195 & S. pimpinellifolium & $15,00 \mathrm{e}$ & $0,00 \mathrm{a}$ & $0,00 \mathrm{a}$ & $6,00 \mathrm{~b}$ & $20,00 \mathrm{~b}$ & $20,0 \mathrm{c}$ \\
\hline CNPH 1012 & S. lycopersicum & $15,00 \mathrm{e}$ & $0,00 \mathrm{a}$ & $0,00 \mathrm{a}$ & $15,00 \mathrm{f}$ & $0,00 \mathrm{a}$ & $0,0 \mathrm{a}$ \\
\hline CNPH 0969 & S. lycopersicum & $15,00 \mathrm{e}$ & $0,00 \mathrm{a}$ & $0,00 \mathrm{a}$ & $14,67 \mathrm{f}$ & $0,33 \mathrm{a}$ & $6,7 \mathrm{~b}$ \\
\hline CNPH 0668 & S. lycopersicum & $15,00 \mathrm{e}$ & $0,00 \mathrm{a}$ & $0,00 \mathrm{a}$ & $15,00 \mathrm{f}$ & $0,00 \mathrm{a}$ & $0,0 \mathrm{a}$ \\
\hline CNPH 0698 & S. lycopersicum & $15,00 \mathrm{e}$ & $0,00 \mathrm{a}$ & $0,00 \mathrm{a}$ & $15,00 \mathrm{f}$ & $0,00 \mathrm{a}$ & $0,0 \mathrm{a}$ \\
\hline CNPH 0707 & S. lycopersicum & $15,00 \mathrm{e}$ & $0,00 \mathrm{a}$ & $0,00 \mathrm{a}$ & $15,00 \mathrm{f}$ & $0,00 \mathrm{a}$ & $0,0 \mathrm{a}$ \\
\hline CNPH 0717 & S. lycopersicum & $15,00 \mathrm{e}$ & $0,00 \mathrm{a}$ & $0,00 \mathrm{a}$ & $15,00 \mathrm{f}$ & $0,00 \mathrm{a}$ & $0,0 \mathrm{a}$ \\
\hline CNPH 0934 & S. peruvianum & $15,00 \mathrm{e}$ & $0,00 \mathrm{a}$ & $0,00 \mathrm{a}$ & $15,00 \mathrm{f}$ & $0,00 \mathrm{a}$ & $0,0 \mathrm{a}$ \\
\hline CNPH 0854 & S. lycopersicum & $15,00 \mathrm{e}$ & $0,00 \mathrm{a}$ & $0,00 \mathrm{a}$ & $15,00 \mathrm{f}$ & $0,00 \mathrm{a}$ & $0,0 \mathrm{a}$ \\
\hline CNPH 0871 & S. lycopersicum & $15,00 \mathrm{e}$ & $0,00 \mathrm{a}$ & $0,00 \mathrm{a}$ & $15,00 \mathrm{f}$ & $0,00 \mathrm{a}$ & $0,0 \mathrm{a}$ \\
\hline CNPH 0875 & S. lycopersicum & $15,00 \mathrm{e}$ & $0,00 \mathrm{a}$ & $0,00 \mathrm{a}$ & $15,00 \mathrm{f}$ & $0,00 \mathrm{a}$ & $0,0 \mathrm{a}$ \\
\hline CNPH 0876 & S. lycopersicum & $15,00 \mathrm{e}$ & $0,00 \mathrm{a}$ & $0,00 \mathrm{a}$ & $15,00 \mathrm{f}$ & $0,00 \mathrm{a}$ & $0,0 \mathrm{a}$ \\
\hline CNPH 0940 & S. peruvianum & $15,00 \mathrm{e}$ & $0,00 \mathrm{a}$ & $0,00 \mathrm{a}$ & $15,00 \mathrm{f}$ & $0,00 \mathrm{a}$ & $0,0 \mathrm{a}$ \\
\hline CNPH 0784 & S. peruvianum & $15,00 \mathrm{e}$ & $0,00 \mathrm{a}$ & $0,00 \mathrm{a}$ & $15,00 \mathrm{f}$ & $0,00 \mathrm{a}$ & $0,0 \mathrm{a}$ \\
\hline CNPH 0937 & S. peruvianum & $15,00 \mathrm{e}$ & $0,00 \mathrm{a}$ & $0,00 \mathrm{a}$ & $15,00 \mathrm{f}$ & $0,00 \mathrm{a}$ & $0,0 \mathrm{a}$ \\
\hline CNPH 0803 & S. lycopersicum & $15,00 \mathrm{e}$ & $0,00 \mathrm{a}$ & $0,00 \mathrm{a}$ & $15,00 \mathrm{f}$ & $0,00 \mathrm{a}$ & $0,0 \mathrm{a}$ \\
\hline CNPH 0935 & S. peruvianum & $15,00 \mathrm{e}$ & $0,00 \mathrm{a}$ & $0,00 \mathrm{a}$ & $6,00 \mathrm{~b}$ & $96,00 \mathrm{i}$ & $80,0 \mathrm{f}$ \\
\hline CNPH 0625 & S. lycopersicum & $15,00 \mathrm{e}$ & $0,00 \mathrm{a}$ & $0,00 \mathrm{a}$ & $15,00 \mathrm{f}$ & $0,00 \mathrm{a}$ & $0,0 \mathrm{a}$ \\
\hline CNPH 1122 & S. habrochaites & $15,00 \mathrm{e}$ & $0,00 \mathrm{a}$ & $0,00 \mathrm{a}$ & $15,00 \mathrm{f}$ & $0,00 \mathrm{a}$ & $0,0 \mathrm{a}$ \\
\hline CNPH 1112 & S. habrochaites & $15,00 \mathrm{e}$ & $0,00 \mathrm{a}$ & $0,00 \mathrm{a}$ & $5,67 \mathrm{~b}$ & $20,00 \mathrm{~b}$ & $20,0 \mathrm{c}$ \\
\hline CNPH 1020 & S. lycopersicum & $15,00 \mathrm{e}$ & $0,00 \mathrm{a}$ & $0,00 \mathrm{a}$ & $15,00 \mathrm{f}$ & $0,00 \mathrm{a}$ & $0,0 \mathrm{a}$ \\
\hline CNPH 1013 & S. lycopersicum & $15,00 \mathrm{e}$ & $0,00 \mathrm{a}$ & $0,00 \mathrm{a}$ & $15,00 \mathrm{f}$ & $0,00 \mathrm{a}$ & $0,0 \mathrm{a}$ \\
\hline CNPH 1014 & S. lycopersicum & $15,00 \mathrm{e}$ & $0,00 \mathrm{a}$ & $0,00 \mathrm{a}$ & $15,00 \mathrm{f}$ & $0,00 \mathrm{a}$ & $0,0 \mathrm{a}$ \\
\hline CNPH 0101 & S. peruvianum & $15,00 \mathrm{e}$ & $0,00 \mathrm{a}$ & $0,00 \mathrm{a}$ & $15,00 \mathrm{f}$ & $0,00 \mathrm{a}$ & $0,0 \mathrm{a}$ \\
\hline CNPH 0010 & S. lycopersicum & $15,00 \mathrm{e}$ & $0,00 \mathrm{a}$ & $0,00 \mathrm{a}$ & $15,00 \mathrm{f}$ & $0,00 \mathrm{a}$ & $0,0 \mathrm{a}$ \\
\hline CNPH 0427 & S. lycopersicum & $15,00 \mathrm{e}$ & $0,00 \mathrm{a}$ & $0,00 \mathrm{a}$ & $15,00 \mathrm{f}$ & $0,00 \mathrm{a}$ & $0,0 \mathrm{a}$ \\
\hline CNPH 0417 & S. habrochaites & $15,00 \mathrm{e}$ & $0,00 \mathrm{a}$ & $0,00 \mathrm{a}$ & $15,00 \mathrm{f}$ & $0,00 \mathrm{a}$ & $0,0 \mathrm{a}$ \\
\hline CNPH 0378 & S. lycopersicum & $15,00 \mathrm{e}$ & $0,00 \mathrm{a}$ & $0,00 \mathrm{a}$ & $15,00 \mathrm{f}$ & $0,00 \mathrm{a}$ & $0,0 \mathrm{a}$ \\
\hline CNPH 0437 & S. lycopersicum & $15,00 \mathrm{e}$ & $0,00 \mathrm{a}$ & $0,00 \mathrm{a}$ & $15,00 \mathrm{f}$ & $0,00 \mathrm{a}$ & $0,0 \mathrm{a}$ \\
\hline CNPH 0431 & S. lycopersicum & $15,00 \mathrm{e}$ & $0,00 \mathrm{a}$ & $0,00 \mathrm{a}$ & $15,00 \mathrm{f}$ & $0,00 \mathrm{a}$ & $0,0 \mathrm{a}$ \\
\hline CNPH 0376 & S. lycopersicum & $15,00 \mathrm{e}$ & $0,00 \mathrm{a}$ & $0,00 \mathrm{a}$ & $15,00 \mathrm{f}$ & $0,00 \mathrm{a}$ & $0,0 \mathrm{a}$ \\
\hline CNPH 1453 & S. peruvianum & $15,00 \mathrm{e}$ & $0,00 \mathrm{a}$ & $0,00 \mathrm{a}$ & $15,00 \mathrm{f}$ & $0,00 \mathrm{a}$ & $0,0 \mathrm{a}$ \\
\hline CNPH 1463 & S. peruvianum & $15,00 \mathrm{e}$ & $0,00 \mathrm{a}$ & $0,00 \mathrm{a}$ & $15,00 \mathrm{f}$ & $0,00 \mathrm{a}$ & $0,0 \mathrm{a}$ \\
\hline CNPH 1464 & S. peruvianum & $15,00 \mathrm{e}$ & $0,00 \mathrm{a}$ & $0,00 \mathrm{a}$ & $15,00 \mathrm{f}$ & $0,00 \mathrm{a}$ & $0,0 \mathrm{a}$ \\
\hline CNPH 1465 & S. peruvianum & $15,00 \mathrm{e}$ & $0,00 \mathrm{a}$ & $0,00 \mathrm{a}$ & $15,00 \mathrm{f}$ & $0,00 \mathrm{a}$ & $0,0 \mathrm{a}$ \\
\hline CNPH 1467 & S. peruvianum & $15,00 \mathrm{e}$ & $0,00 \mathrm{a}$ & $0,00 \mathrm{a}$ & $15,00 \mathrm{f}$ & $0,00 \mathrm{a}$ & $0,0 \mathrm{a}$ \\
\hline CNPH 1561 & S. lycopersicum & $15,00 \mathrm{e}$ & $0,00 \mathrm{a}$ & $0,00 \mathrm{a}$ & $8,00 \mathrm{c}$ & $24,0 \mathrm{~b}$ & $20,0 \mathrm{c}$ \\
\hline CNPH 1563 & S. lycopersicum & $15,00 \mathrm{e}$ & $0,00 \mathrm{a}$ & $0,00 \mathrm{a}$ & $12,67 \mathrm{~d}$ & $20,0 \mathrm{~b}$ & $20,0 \mathrm{c}$ \\
\hline $\mathrm{CV}(\%)$ & & 6,91 & 20,84 & 22,09 & 4,68 & 22,3 & 3,41 \\
\hline
\end{tabular}


algumas células 48 horas após a inoculação com S. solani, resultando em lesões pequenas que em nada afetavam o desenvolvimento normal da planta. A presença de resistência horizontal, poligênica ou quantitativa pode estar associada com os menores níveis de severidade e/ou diferentes níveis de resistência observados entre os genótipos avaliados.

Alguns genótipos apresentaram níveis elevados de suscetibilidade no primeiro ensaio de avaliação do germoplasma de Solanum (secção Lycopersicon). Entretanto, estes não foram avaliados de maneira mais refinada (i.e. utilizando-se os componentes epidemiológicos), uma vez que o objetivo do primeiro ensaio foi fazer uma triagem da reação às espécies de Stemphylium no maior número possível de genótipos (ou seja, em larga escala). No segundo ensaio, no entanto, os genótipos mais promissores foram avaliados novamente e de maneira mais criteriosa empregando-se uma escala de notas e utilizando-se um maior número de repetições e com mais variáveis epidemiológicas.

Os genótipos que apresentaram os menores valores de AACPD no presente trabalho despontam como as principais fontes de resistência aos patógenos. Os genótipos que apresentaram suscetibilidade a apenas uma espécie na etapa inicial de avaliação (ex. 'CNPH-0800'), mostraram-se suscetíveis aos dois isolados na segunda etapa de avaliação. O genótipo 'CNPH-1123', que demonstrou resistência aos dois patógenos no primeiro experimento foi suscetível no segundo ensaio. Estes resultados indicam que a reação apresentada inicialmente deveu-se a escapes, que, em geral, foram pouco numerosos, como indicado pela estabilidade da reação dos genótipos resistentes nos dois ensaios. Esta estabilidade da reação pode ser demonstrada por experimentos realizados anteriormente por Reis \& Boiteux (2006b), que identificaram o genótipo 'CNPH-1123' como suscetível aos dois patógenos.

Observou-se correlação significativa entre ID e AACPD para ambos os isolados testados, e de média a alta correlação de PI com ID e AACPD. Ou seja, quanto maior o PI, menores serão os valores dos outros dois parâmetros. Neste contexto, os parâmetros que melhor discriminaram os genótipos quanto à resistência foram a AACPD e o ID. Estes podem ser utilizados individualmente ou em conjunto nos trabalhos de seleção de genótipos ou de populações segregantes de tomate para resistência a Stemphylium spp.

A ocorrência de plantas suscetíveis e resistentes em um mesmo genótipo (especialmente em genótipos de $S$. lycopersicum) sugere a segregação do material, ou também o efeito de genes modificadores que podem estar interferindo na expressão do gene $\mathrm{Sm}$. Cruzamentos naturais (embora raros), também têm sido mencionados como uma fonte de variação dentro de genótipos resistentes e/ou suscetíveis ou mistura física durante extração e armazenamento de sementes (Kurozawa \& Mussi, 1995). No entanto, na maioria dos casos, o motivo mais provável pode ser variabilidade natural presente, especialmente, em espécies alógamas e/ou com mecanismos de auto-incompatibilidade (ex. S. peruvianum). Desta forma, a presença de segregação dentro do genótipo pode indicar variabilidade natural para fatores de resistência aos patógenos presente na população de plantas que ocupavam o local no momento da coleta.

Genótipos que foram resistentes na primeira etapa de avaliação, mas que na segunda etapa de seleção foram classificados como suscetíveis reforçam a necessidade da repetição dos experimentos para a confirmação da resistência, mesmo sob condições controladas. Segundo Mello (1995), a avaliação de genótipos sob várias condições ambientais (favoráveis e desfavoráveis ao desenvolvimento da doença) é de grande importância para confirmar a estabilidade da resistência. De acordo com Paula \& Oliveira (2001) é necessária também a avaliação para resistência em diversas localidades e com diferentes intensidades da doença para a confirmação desta característica.

Muitos dos genótipos classificados como resistentes às duas espécies de Stemphylium apresentaram, no segundo ensaio, índices de doença e AACPD nulos (valores $=$ zero) e PI longos A existência de diversidade genética para resistência em Solanum (secção Lycopersicon) a diferentes espécies de Stemphylium é de extremo interesse para os programas de melhoramento genético, especialmente no caso de superação da resistência do gene $S m$ por novas raças (ou patótipos) destes patógenos. Esta diversidade poderá permitir que diferentes fatores de resistência possam ser "piramidados" em cultivares comerciais de tomate e/ou servir de genes alternativos no caso de surgimentos de isolados capazes de superar a resistência controlada pelo gene $\mathrm{Sm}$. Entretanto, tal superação ainda não ocorreu desde que o gene de resistência $S m$ foi inserido em genótipos comerciais, na década de 1950 (Scott, 1999), indicando a alta estabilidade desta resistência. A durabilidade do gene $S m$ pode também estar sendo favorecida pela aplicação de fungicidas recomendados para outras doenças do tomateiro, que podem também controlar as potenciais variantes de virulência dentro destas duas espécies de Stemphylium (Kurozawa \& Mussi, 1995) e eventualmente eliminar dos campos de produção isolados virulentos a este gene de resistência. De qualquer forma, os resultados obtidos no presente estudo fornecem informações úteis sobre novas promissoras fontes (comerciais e selvagens) de resistência aos dois patógenos. Esta potencial diversidade de fatores de resistência para Stemphylium pode ser útil em futuras ações de pesquisa dentro de programas de melhoramento genético do tomateiro bem como para o manejo integrado da doença.

\section{REFERÊNCIAS}

BEHARE J; LATERROT H; SARFATTI M; ZAMIR D. 1991. Restriction fragment length polymorphism mapping of the Stemphylium resistance gene in tomato. Molecular PlantMicrobe Interactions 4: 489-492.

BENTES JLS; MATSUOKA K. 2005. Histologia da interação Stemphylium solani e tomateiro. Fitopatologia Brasileira 30: 224-231.

BLANCARD D; LATERROT H. 1986. Les Stemphylia rencontrés sur le tomate. Phytopathologia Mediterranea 25: 140-144.

BOITEUX LS; HENZ GP; GIORDANO LB. 1993. Solanum lycocarpum: a natural host of Stemphylium solani. Plant Disease 77: 846.

BOFF P; ZAMBOLIM L; RIBEIRO DO VALE FX. 1991. Escalas para avaliação de severidade da mancha de estenfílio (Stemphylium solani) e da pinta preta (Alternaria solani) em tomateiro. 
Fitopatologia Brasileira 16: 280-283.

DALLA-PRIA M.; AMORIM L; BERGAMIN FILHOA. 2003. Quantificação de componentes monocíclicos da antracnose do feijoeiro. Fitopatologia Brasileira 28: 401-407.

DALBOSCO M.; SCHONS J; PRESTES AM. 2002. Incidência e índice de doença do mosaico do trigo em cereais de inverno e em gramíneas de verão, associados ao Polymyxa graminis. Fitopatologia Brasileira 27: 48-52.

ELLIS MB; GIBSON IAS. 1975a. Stemphylium lycopersici. CMI Descriptions of Pathogenic Fungi and Bacteria Number 471. Commonwealth Mycological Institute, Ferry Lane, Kew, Surrew, England, 2pp.

ELLIS MB; GIBSON IAS. 1975b. Stemphylium solani. CMI Descriptions of Pathogenic Fungi and Bacteria Number 472. Commonwealth Mycological Institute, Ferry Lane, Kew, Surrew, England, 2pp.

HANNON CI; WEBER GF. 1955. A leaf spot of tomato caused by Stemphylium floridanum sp. nov. Phytopathology 45: 11-16.

FRY WE. 1978.Quantification of general resistance of potato cultivars and fungicide effects for integrated control of potato late blight. Phytopathology 68: 1650-1655.

GIORDANO LB; ARAGÃO FAS; BOITEUX LS. 2003. Melhoramento genético do tomateiro. Informe Agropecuário 24: 43-57.

HENDRIX JW; FRAZIER WA. 1949. Studies on the inheritance of Stemphylium resistance in tomatoes. Honolulu: UNIVERSITY OF HAWAII (Technical Bulletin, 8).

HENDRIX JW; KIKUTA K; FRAZIER WA. 1946. Breeding tomatoes for resistance to grey leaf spot in Hawaii. Proceedings of the American Society for Horticultural Sciences 46: 294-300.

IAMSUPASIT N; CHAKRABORTY S; CAMERON DF; ADKINS SW. 1993.
Components of quantitative resistance to anthracnose (Colletotrichum gloeosporioides) in tetraploid accessions of the pasture legume Stylosanthes hamata. Australian Journal of Experimental Agriculture 33: 855-860.

KUROZAWA C; MUSSI L. 1995. Avaliação de cultivares e híbridos de tomateiro à manchade-estenfílio. Summa Phytopathologica 21: 199-201.

LATERROTH. 1976. Localisation chromosomique de $I 2$ chez la tomate controlant la resistance au pathotype 2 de Fusarium oxysporum $\mathrm{f}$. sp. lycopersici. Annales d'Amelioration des Plantes 26: 485-491.

LATERROT H; BLANCARD D. 1983. Criblage d'une série de lignées et d'hybrides F1 de tomate pour la résistance à la stemphyliose. Phytopathologia Mediterranea 22: 188-193.

LOPES CA; REIS A.; BOITEUX LS. 2005. Doenças fúngicas. In: ÁVILA AC; LOPES CA. Doenças Fúngicas do Tomateiro. Brasília: EMBRAPA HORTALIÇAS, p. 17-52.

MCKINNEY HH. 1923. Influence of soil temperature and moisture on infection of wheat seedlings by Helminthosporium sativum. Journal of Agricultural Research 26: 195218.

MELLO SCM. 1995. Resistência do tomateiro à mancha-bacteriana. Brasília: UnB. 112p. (Tese doutorado).

PAULA RS; OLIVEIRA WF. 2001. Resistência de tomateiro (Lycopersicon esculentum Mill.) a Stemphylium solani. Pesquisa Agropecuária Tropical 31: 139-145.

PEDROSA RA; MAFFIA LA; MIZUBUTI ESG; BROMMONSCHENKEL SH. 2004. Componentes de resistência em cebola a Colletotrichum gloeosporioides. Fitopatologia Brasileira 29: 606-613.

PELLETIER JR; FRY WE. 1989. Characterization of resistance to early blight in three potato cultivars: incubation period, lesion expansion rate, and spore production. Phytopathology 79: 511-517.

REIS A; BOITEUX LS. 2006a. Mancha-deestenfilio: ressurgimento de um antigo problema do tomateiro. Brasília: EMBRAPA HORTALIÇAS. Circular Técnica 41. 8p.

REIS A; BOITEUX LS. 2006b. Resistência de acessos de Lycopersicon a Stemphylium solani e S. lycopersici. Brasília: EMBRAPA HORTALIÇAS. Boletim de Pesquisa e Desenvolvimento 22. 12p.

RODRIGUES TTMS. 2005. Esporulação in vitro de Alternaria solani. Viçosa: Universidade Federal de Viçosa. 35p. (Tese mestrado).

ROTEM J; COHEN Y; WAHL I. 1966. A new tomato foliage disease in Israel caused by Stemphylium botryosum. Canadian Journal of Plant Sciences 6: 265-270.

SANTOS JRM. 1997. Methodology for screening tomato for Fusarium Wilt, Verticillium Wilt, Gray Leaf Spot, Early Blight and Septoria Leaf Blight. In: PROCEEDINGS OF THE INTERNATIONAL SYMPOSIUM ON TROPICAL TOMATO DISEASES 1996, ASHS: IPA. Alexandria, EUA: p. 164- 166.

SCOTT JW. 1999. University of Florida tomato breeding accomplishments and future directions. Soil and Crop Sciences Society of Florida Proceedings 58: 8-11.

SILVA FAS; AZEVEDO CAV. 2002. Versão do programa computacional Assistat para o sistema operacional Windows. Revista Brasileira de Produtos Agroindustriais 4: 71-78.

WEBER GF. 1930. Gray leaf spot of tomato caused by Stemphylium solani, sp. nov. Phytopathology 20: 513-518.

WILTSHIRE SP. 1938. The original and modern conceptions of Stemphylium. Transactions of the British Mycological Society 21: 211-239. 